\title{
A novel method to measure particle sinking velocity in vitro, and its comparison to three other in vitro methods
}

\author{
Helle Ploug 1,2, Anja Terbrüggen ${ }^{1}$, Anna Kaufmann ${ }^{1}$, Dieter Wolf-Gladrow ${ }^{1}$, and Uta Passow $1,3^{*}$ \\ ${ }^{1}$ Alfred Wegener Institute for Polar and Marine Research, Am Handelshafen 12, D - 27570 Bremerhaven, Germany \\ ${ }^{2}$ Stockholm University, Dept of Botany, Lilla Frescativägen 5, 10691 Stockholm \\ ${ }^{3}$ Marine Science Institute, University of California Santa Barbara, CA 93106, USA
}

\begin{abstract}
We introduce a novel, simple method to measure sinking velocity of particles and aggregates in roller tanks. Using this noninvasive method, it is possible to follow changes in sinking velocities on the same aggregates during time and to make paired measurements of aggregate sinking velocity and composition. Particles and aggregates are video recorded in roller tanks, and their sinking velocity is derived from the orbital trajectories. This new method is compared with three other methods (using roller tanks, a vertical flow system, and a sedimentation column), which have not previously been inter-calibrated. Agar spheres and diatom aggregates were used as model particles in all experimental systems. No method showed significantly different sinking velocities of agar spheres compared with those calculated by theory. Paired measurements showed that sinking velocities from 70 to $700 \mathrm{~m} \mathrm{~d}^{-1}$ were linearly correlated between different methods. Highest sinking velocities were measured in a sedimentation column followed by those measured in roller tanks and in the vertical flow system, respectively. The average difference of sinking velocity measured with the different methods ranged from $8 \%$ to $11 \%$ for agar spheres, and up to $20 \%$ for diatom aggregates.
\end{abstract}

The production of organic matter in the euphotic zone and its export to the deep sea and sediments is a significant mechanism by which $\mathrm{CO}_{2}$ from the atmosphere is sequestered by the ocean (Volk and Hoffert 1985). Fast-sinking marine snow $>0.5$ $\mathrm{mm}$ formed by coagulation of phytoplankton, transparent exopolymer particles (TEP), detritus, and fecal pellets comprises a significant fraction of this vertical carbon flux in the ocean (Alldredge and Silver 1988; Simon et al. 2002; Turner 2002). Sinking velocities of fecal pellets and marine snow varies appreciably and cannot be predicted by Stoke's law because their Reynolds numbers are well above 0.5 , their geometry is non-spherical, and marine snow is porous (Alldredge and Gotschalk 1988; Khelifa and Hill 2006; Ploug et al. 2008).

In situ sinking velocity of marine snow varies between 20 and $1000 \mathrm{~m} \mathrm{~d}^{-1}$ (Billet et al. 1983; Asper 1987; Alldredge and

*Corresponding author: E-mail: uta.passow@lifesci.ucsb.edu

\section{Acknowledgment}

This study was supported by the Helmholz Association (to HP) and the Alfred Wegener Institute for Polar and Marine Research, and Marum (the German Research Council). We thank Nico Nowald for assistance during measurements and Bruce Logan for discussions. We also thank an anonymous reviewer for improving the manuscript. This is AWI publication no. 18583.

DOI 10:4319/lom.2010.8.386
Gotschalk 1989; Berelson 2002). Although large variations occur for similar-sized marine snow, sinking velocity tends to increase with increasing aggregate size (Alldredge and Gotschalk 1988). Sinking velocity of aggregates formed by uniform sources of primary particles, e.g., a diatom culture, increases significantly with increasing aggregate size (Li et al. 2003; Engel and Schartau 1999; Ziervogel and Forster 2005), but sinking velocities measured across different particle types depend on source, density, and age rather than on size (Ploug et al 2008). Marine aggregates are fractal, hence, their porosity increases with increasing aggregate size (Alldredge and Gotschalk 1988; Logan and Wilkinson 1990). Sinking velocity of similar-sized aggregates and fecal pellets is largely controlled by their excess density, which depends on the solid matter density, i.e., composition of primary particles, transparent exopolymer particles (TEP), porosity, and fractal dimension (Azetsu-Scott and Passow 2004; Engel and Schartau 1999; Johnson et al. 1996; Khelifa and Hill 2007). These parameters vary significantly between different aggregate and fecal pellet types. Hence, our understanding of aggregate sinking velocity and its influence on vertical fluxes depends on empirical measurements.

Quantification of sinking velocity has often been limited to that measured in a sedimentation column, which is simple to use but unfortunately often excludes replicate measurements 
and additional compositional analysis of the same aggregate, because aggregates collapse or disaggregate after sedimentation and re-suspension. Here, we present a new noninvasive and simple method to measure sinking velocity of marine snow directly in roller tanks, where large particles are kept suspended. Aggregates can easily be collected for compositional analysis afterward. We compare results of our new methods with three other methods, which have not been inter-calibrated previously.

\section{Materials and procedures}

Model particles-Differentially sized agar spheres were used as model particles. Agar spheres were produced from a 1\% agar solution with a salinity of 0 or 32 PSU (produced from distilled water with $\mathrm{NaCl}$ ) briefly heated to boiling point and cooled down to $40^{\circ} \mathrm{C}$. At this temperature, the agar solution was trickled, by use of a pipette, into a thin layer of paraffin oil lying on top of (salt) water (Cronenberg 1994; Ploug et al. 2002). Small, almost perfect spheres were produced by one drop, larger spheres by two drops on the same spot, etc. The smallest spheres were $1.3 \mathrm{~mm}$, and the largest were $4.8 \mathrm{~mm}$ in diameter. These agar spheres are solid and the same spheres could be used in all four experimental systems to measure their sinking velocity. Their excess density $\left(0.0011 \mathrm{~g} \mathrm{~cm}^{-3}\right)$ was determined by the volume-specific weight difference of the solidified agar and water at $15^{\circ} \mathrm{C}$.

Diatom aggregates were formed using a Skeletonema costatum culture, which had been grown in $\mathrm{F} / 2$ medium at $15^{\circ} \mathrm{C}$ during 4 weeks at a $12 \mathrm{~h}: 12 \mathrm{~h}$ light:dark cycle (Guillard and Ryther 1962). Aggregates $>1 \mathrm{~mm}$ were produced in $4 \mathrm{~L}$ large roller tanks rotating at $5 \mathrm{rpm}$ in darkness during $6 \mathrm{~d}$.

Size determination-Dimensions of agar spheres and aggregates were determined directly under a dissection microscope with a calibrated ocular, while they were in a vertical flow system (see below). Agar spheres were perfect spheres. Diatom aggregates, however, had ellipsoid geometry and were turned during measurements that allowed for size-determination of all three axes. The volume of aggregates was calculated assuming an ellipsoid: $V=4 / 3 \times \pi \times a \times b \times c$, where $a, b$, and $c$ are the half axes. The equivalent spherical diameter (ESD) was calculated as $\mathrm{ESD}=2 \times(3 \mathrm{~V} / 4 \pi)^{1 / 3}$.

Sinking velocity comparisons-Sinking velocities of agar spheres and diatom aggregates were measured sequentially in three experimental systems for comparison: 1) video recording of aggregate trajectories in roller tanks; 2) a vertical flow system in which aggregate sinking velocity is opposed and balanced by an upward-directed flow velocity (Ploug and Jørgensen 1999); and 3) a sedimentation column in which the sinking velocity is measured following the descent of single particles per unit time. We also calculated theoretical sinking velocities.

The sinking velocity of each agar sphere was first measured in the vertical flow system, where the size was also determined, then in the sedimentation column and finally in the roller tanks. This procedure was followed to sort agar spheres by size in different roller tanks. One agar sphere of each size was added to each roller tank whereby their identity were known also after solid body rotation of the water in tanks was established ( $>3 \mathrm{~h}$ rotation time) and video recording were performed. Solid body rotation is a prerequisite for accurate measurements and calculations of particle sinking velocity in roller tanks.

Paired measurements of sinking velocity of six to eight diatom aggregates were done (a) first in the vertical flow system and then in the sedimentation column, or (b) first in roller tanks and then in the sedimentation column. It was not possible to measure sinking velocity of the very same aggregate by all three methods due to disaggregation and aggregation during handling.

The agar spheres or diatom aggregates were transferred from one system to the other by use of a wide bore pipette. All measurements were conducted in a temperature constant room $\left(15^{\circ} \mathrm{C}\right)$. We used distilled or salt water at $32 \%$ as a liquid. A large volume (50 L) of salt water was produced initially, mixed and used in all experimental systems.

Sinking velocity measurements in roller tanks

Theory-Particle trajectories in a roller tank are complicated when the tank begins to spin (Jackson 1994). After a transient time, $\tau(\mathrm{s})$, of the order $\mathrm{a}^{2} / v$ where a $(\mathrm{cm})$ is the cylinder radius and $v\left(\mathrm{~cm}^{2} \mathrm{~s}^{-1}\right)$ is the kinematic viscosity of water, the flow of the water shows 'solid body rotation' around the cylinder axis, i.e., $\mathrm{v}_{\mathrm{r}}=0, \mathrm{v}_{\phi}=\omega \times \mathrm{r}, \mathrm{v}_{\mathrm{z}}=0$ where $\mathrm{r}, \phi, \mathrm{z}$ are cylinder coordinates, $\omega=2 \pi / T\left(s^{-1}\right)$ is the rotation rate, and $T(s)$ is the rotation period. The theoretical time scale, $\tau$, is $2.4 \mathrm{~h}$ for a roller tank with radius $10 \mathrm{~cm}$ and a kinematic viscosity $v=1.14 \times 10^{-2}$ $\mathrm{cm}^{2} \mathrm{~s}^{-1}$ at $15^{\circ} \mathrm{C}$ and zero salinity. The kinematic viscosity, $v$, decreases with increasing temperature and increases with increasing salinity.

At steady state, the particles follow circular trajectories in $\mathrm{z}$ = constant planes (Tooby et al. 1977):

$$
\begin{gathered}
x(t)=x_{b}-R \sin \left(\omega t-\theta_{0}\right) \\
y(t)=R \cos \left(\omega t-\theta_{0}\right)
\end{gathered}
$$

where $R$ is the radius of the circle and $\theta_{0}$ is the initial angle. The tank rotates counter-clockwise. The center of the circle $\left(x_{b}, 0\right)$ is located at a distance $x_{b}(\mathrm{~cm})$ to the right of the cylinder axis (in the half cylinder where the fluid flow is upward) on the horizontal axis that crosses the cylinder axis. The distance $\mathrm{x}_{\mathrm{b}}$ is given by (Tooby et al. 1977; Jackson 1994)

$$
x_{b}=\frac{w_{s}}{\omega}=\mathrm{w}_{\mathrm{s}} \times \mathrm{T} /(2 \pi)
$$

The sinking velocity of the particle $\mathrm{w}_{\mathrm{s}}\left(\mathrm{cm} \mathrm{s}^{-1}\right)$ can be determined from $T$ and $\mathrm{x}_{\mathrm{b}}$. The distance $\mathrm{x}_{\mathrm{b}}$ will be derived from several observations of particle positions combined with a leastsquares estimation of the center of the particle orbit (see below).

The distance $\mathrm{x}_{\mathrm{b}}$ was estimated as follows from a number (10 to 20) of particle positions $\left(\mathrm{x}_{\mathrm{n}}, \mathrm{y}_{\mathrm{n}}\right), \mathrm{n}=1,2, \ldots, \mathrm{N}$ read from 
photographs of the roller tank (Fig. 1). We first derive a rough estimate $\left(\mathrm{x}_{\mathrm{re}}, \mathrm{y}_{\mathrm{re}}\right)$ of the position of the circle center $\left(\mathrm{x}_{\mathrm{b}}, \mathrm{y}_{\mathrm{b}}\right)$ by averaging over all particle positions (assuming that positions are nearly isotropically distributed around the center). For a given center position $\left(\mathrm{x}_{\mathrm{b}}, \mathrm{y}_{\mathrm{b}}\right)$, we calculate the circle radius

$$
R_{n}=\sqrt{\left(x_{n}-x_{b}\right)^{2}+\left(y_{n}-y_{b}\right)^{2}}
$$

for all particle positions $\left(\mathrm{x}_{\mathrm{n}}, \mathrm{y}_{\mathrm{n}}\right), \mathrm{n}=1,2, \ldots \mathrm{N}$. From these radii $\mathrm{R}_{\mathrm{n}}$ we calculate the mean $\mathrm{R}_{\text {mean }}$ and the variance.

Now we vary the center position $\left(\mathrm{x}_{\mathrm{b}}, \mathrm{y}_{\mathrm{b}}\right)$ in a range around our rough estimate. Assuming a maximal error of $\pm 80 \%$ of the mean radius $\mathrm{R}_{\text {mean }}$ in our rough estimate of the center position, we vary $\mathrm{x}_{\mathrm{b}}$ between $\mathrm{x}_{\mathrm{re}},-0.8 \times \mathrm{R}_{\text {mean }}$ and $\mathrm{x}_{\mathrm{re}},+0.8 \times \mathrm{R}_{\text {mean }}$ and $\mathrm{y}_{\mathrm{b}}$ between $\mathrm{y}_{\mathrm{re}^{\prime}},-0.8 \times \mathrm{R}_{\text {mean }}$ and $\mathrm{y}_{\mathrm{re}},+0.8 \times \mathrm{R}_{\text {mean }}$ with resolution $\Delta \mathrm{x}=$ $\Delta \mathrm{y}$. The spatial resolution $\Delta \mathrm{x}$ for this search is determined by the chosen accuracy in $\mathrm{w}_{\mathrm{s}}, \Delta \mathrm{w}_{\mathrm{s}}$, and the given rotation period, T, using Eq. 2

$$
\Delta \mathrm{x}=\Delta \mathrm{w}_{\mathrm{s}} \times \mathrm{T} /(2 \pi)
$$

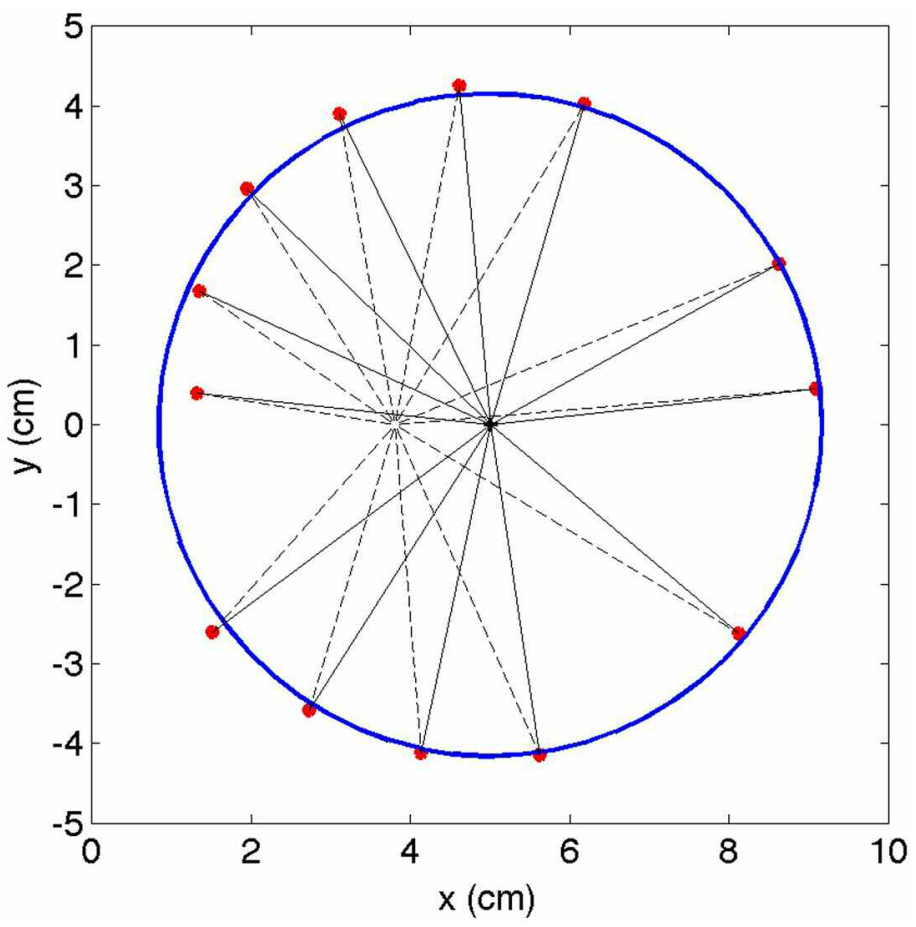

Fig. 1. Example of orbit analysis to derive sinking velocity of particles in roller tanks. The distances between the observed aggregate positions along its orbit (red dots) and a chosen orbit center (at $x=3.8 \mathrm{~cm}, y=0$ $\mathrm{cm}$; linked to observations by broken lines) are squared and summed up. The position of the orbit center is varied on a grid with fine $(0.1 \mathrm{~mm})$ resolution and the corresponding sum of the squared distances is calculated. The point where this sum is minimal is used as the optimal orbit center position (at $x=5 \mathrm{~cm}, y=0 \mathrm{~cm}$; linked to observations by solid lines). The mean distance between the optimal center and the observations is the optimal radius $(4 \mathrm{~cm})$ used to plot the circle (blue solid line) around the orbit center. The distance between the axis of the roller tank at (0.0) and the aggregate's center position is $5 \mathrm{~cm}$. With a rotation rate of $0.083 \mathrm{~s}^{-1}$ ( $5 \mathrm{rpm}$ ), the aggregate's sinking velocity is $5 \mathrm{~cm} \times 0.083 \mathrm{~s}^{-1}=0.41 \mathrm{~cm} \mathrm{~s}^{-1}$ or $180 \mathrm{~m} \mathrm{~d}^{-1}$. which gives $\Delta \mathrm{x}=0.18 \mathrm{~mm}$ for $\Delta \mathrm{w}_{\mathrm{s}}=1 \mathrm{~m} \mathrm{~d}^{-1}$ and a typical rotation period of $100 \mathrm{~s}$. To be on the safe side, we set $\Delta \mathrm{x}=0.1 \mathrm{~mm}$.

Now we calculate the variance of the radii for each center position. Finally, we search for the minimal variance of the radii with respect to the center position and use the corresponding center position as our best estimate. The optimal value for $x_{b}$ is inserted into Eq. 2 to calculate $w_{s}$. Program code: "sinkorbit.m" written in MATLAB for the whole procedure is available from the Web site of Dieter Wolf-Gladrow (www.awi.de/fileadmin/user_upload/Research/Research_Divis ions/Biosciences/Biogeosciences/code/sinkorbit.m). We will call this calculation method the orbit analysis.

Alternatively, we also used the method of Engel and Schartau (1999) to calculate sinking velocities of aggregates in roller tanks. Principally, it is based on the same theory as our method, but only two points of the particle trajectories are used, and these must be nearly vertical to the center line in the upstream region of the roller tank and close to the front of the roller tank when projected distances are not calibrated with regard to depth of the roller tank, i.e., projected distances appear smaller close to the back side of the roller tanks as compared with those in the front close to the camera. This method of calculating sinking velocity from trajectories in roller tanks will be termed the two-point method.

Set-up and calibration procedure of roller tanks-The center of the roller tanks was marked both on the front side as well as on the back side to align the camera exactly along this center line, which is important for calibration of projected distances with depth in roller tanks. The exact depth of the roller tanks was measured. The apparent diameters of the periphery of the front and back side of the water-filled roller tank on the video file were calibrated linearly with depth. The back sides of the roller tanks were covered with black paper to increase the contrast between agar spheres and the surrounding water. Cold light sources with an infra red cut-off filter (Schott KL 2500) were used to illuminate the tanks. During preliminary experiments, we observed that warm light induced circulation instantaneously and caused a large variability on calculated sinking velocities.

The rotation speed of tanks (rpm) has to be set carefully to be able to measure sinking velocity of particles suspended in tanks correctly. If it is too high, particles will go around in circles with the fluid, and measurements are inaccurate. If the rotation speed is too low, particles will sink and collide with the container walls. Only if the rotation speed and sinking velocities are matched so that particles move in small orbits rather than following the large circular motion of the fluid, reliable sinking velocity measurements can be made. The tanks must be completely filled with fluid (no air-bubbles). Air-bubbles induce strong shear within roller tanks, and the trajectories of particles deviate significantly from that of a circle. Our sinking velocity measurements were done $16 \mathrm{~h}$ after the rotation speed of the tanks had been set to ensure steadystate and solid body rotation. Solid body rotation must be 
established in roller tanks before sinking velocity measurements can be made. We experimentally tested the time needed for solid body rotation to be established in our roller tanks to evaluate the accuracy of the theoretically calculated spin-up time of $2.4 \mathrm{~h}$. We filled several tanks with a solution of sodium hydroxide, and after different time intervals, added a few drops of phenolphthalein without modifying rotation speed of the roller tank via a syringe and a needle thrust through the rubber stopper. In a basic solution the colorless phenolphthalein turns pink. Thus, a small pink stain appeared in the roller tank as soon as phenolphthalein was added. This stain remained stable and turned with the water after solid body rotation was established. In the absence of solid body rotation, pink streaks and swirls became visible as turbulence mixed the phenolphthalein into the tank volume. Our tests confirmed that solid body rotation was established already after 2.5 to $3 \mathrm{~h}$.

All recordings of calibrations and aggregates were made using a video camera (Canon Power Shot A70). At least one full orbit of each aggregate was video recorded. Single pictures (JPG files) were extracted using the program xn-View, and imported into Adobe Photoshop. In this program, the pictures were arranged in layers whereby the $x, y$ coordinates of the aggregate at different time points can be directly read using the tools of Photoshop (Fig. 1). A circle, which encompasses all positions of the aggregate through time, was drawn in Photoshop, and its x-coordinate of the center was calculated from the coordinates of its vertical tangents read in Photoshop. Alternatively, the $\mathrm{x}, \mathrm{y}$ coordinates of the aggregate's position during time (which can be read in Photoshop) calibrated with respect to depth (z-plane) within the roller tank, and the rotation period can be entered in the function "sinkorbit.m" which calculates the sinking velocity.

Sinking velocity measurements in the vertical flow system-This experimental set-up was described by Ploug and Jørgensen (1999). In this system, aggregate's sinking velocity is opposed and balanced by an upward-directed flow velocity.

The aggregate is suspended above a horizontally oriented nylon net by a distance equal to that of the particle diameter, i.e., the center of the aggregate is positioned 3 radii away from the net. Its exact position and size is measured under a dissection microscope with a calibrated ocular using a $150 \mathrm{~W}$ halogen lamp with an infrared cut off filter (Schott KL 1500). Under these conditions, the gradients of fluid velocity and solutes at the particle-water interface are similar to those predicted by mass transfer theory for a solid sphere sinking through a stagnant water column (Kiørboe et al. 2002). The flow velocity is calculated as the volume of water passing per unit time divided by the cross-sectional area of the flow chamber.

Sinking velocity measurements in a sedimentation column-A 2L large cylindrical glass tube ( $8 \mathrm{~cm}$ wide) was used as sedimentation column. It was filled with water and allowed to stabilize in a temperature-constant room before each measurement. Agar spheres or diatom aggregates were gently introduced into the column by letting one sphere/aggregate sink through the water inside an inverted Pasteur pipette, which was inserted 0.5 $\mathrm{cm}$ under the air-water interface of the sedimentation column. Its time-dependent descent was followed using a stop-watch over a distance of $20.5 \mathrm{~cm}$ from $6 \mathrm{~cm}$ below the surface until 6 $\mathrm{cm}$ above the bottom of the column.

Calculations of theoretical sinking velocity-For comparison, theoretical sinking velocities of agar spheres and diatom aggregates were calculated from:

$$
U=\left(2 g \Delta \rho V / \rho_{f} C_{D} A\right)^{0.5}
$$

where $U$ is the sinking velocity, $g$ is the acceleration due to gravity, $\Delta \rho$ is the excess density of the agar spheres or aggregates, $V$ is the particle volume, and $\rho_{\mathrm{f}}$ the density of the bulk water. $C_{D}$ is the drag coefficient and $A$ is the cross-sectional area of the agar sphere or aggregate.

The Reynolds number was calculated as (White 1974):

$$
\operatorname{Re}=\frac{d U}{v}
$$

where $d$ is the diameter of the particle or aggregate and $v$ is the kinematic viscosity of (sea) water.

The drag coefficient for Re $>0.5$ was calculated as (White 1974):

\section{Assessment}

$$
C_{D}=\frac{24}{\operatorname{Re}}+\frac{6}{1+\operatorname{Re}^{0.5}}+0.4
$$

Comparison of methods-Measured size-specific sinking velocities of agar spheres and theoretical sinking velocities are shown on Fig. 2. The largest spheres were a few days older than the others. Hence, they were not made of the same stock solution of agar as the others, and they may also have been colonized by bacteria. These factors may have influenced their excess density and consequently their sinking velocity. Theo-

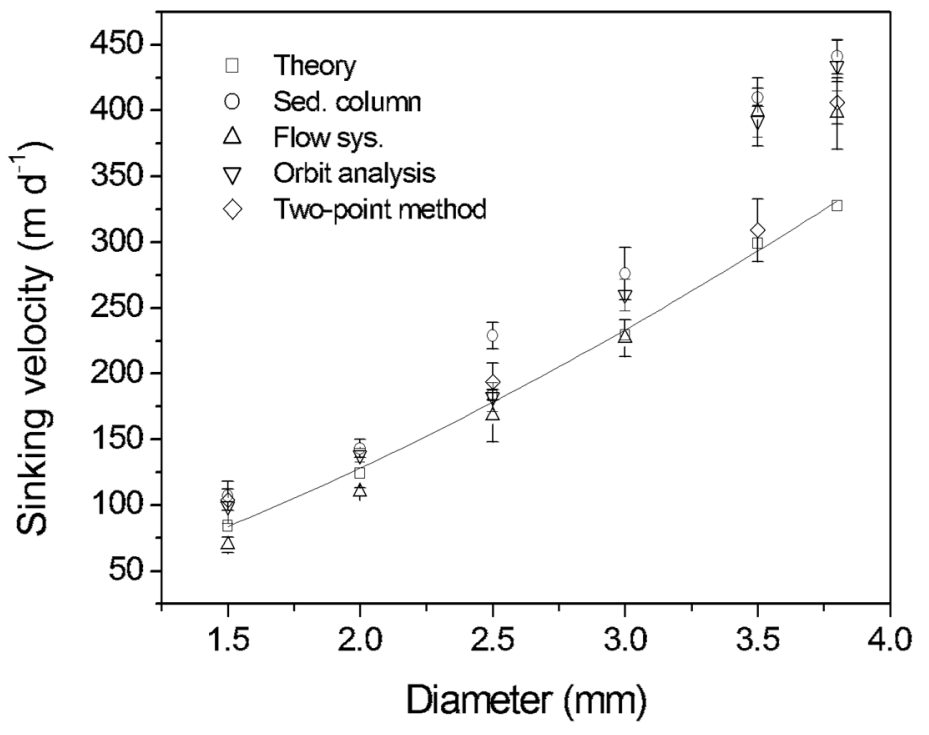

Fig. 2. Sinking velocity of agar spheres as a function of sphere diameter. 

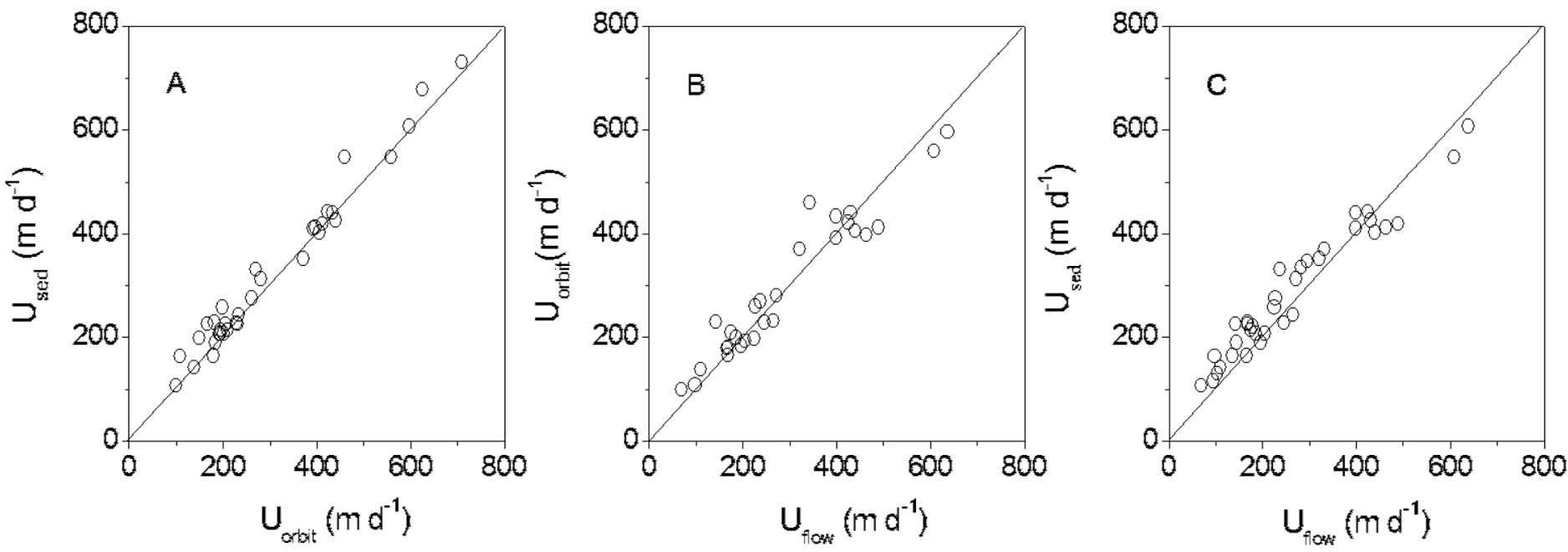

Fig. 3. (A) Comparison of sinking velocity determination in roller tanks using the orbit analysis with those measured in a sedimentation column. (B) Comparison of sinking velocity measurements in the flow system with those measured in roller tanks using the orbit analysis. (C) Comparison of sinking velocity measured in the flow system with those in the sedimentation column.

retical sinking velocity was described by $\mathrm{U}=46 \times \mathrm{d}^{1.48 \pm 0.04}\left(R^{2}=\right.$ $1.00)$, where $U$ is measured in $\mathrm{m} \mathrm{d}^{-1}$ and the diameter, $\mathrm{d}$, is measured in $\mathrm{mm}$. No method yielded significantly different sinking velocity compared with those predicted by theory (Student $t$ test; $P<0.01$ ), when the oldest spheres were excluded from the analysis.

Paired measurements of sinking velocity of single agar spheres derived from the orbit analysis in roller tanks, in the sedimentation column, and in the flow system are shown on Fig. 3. The correlations of sinking velocities were linear from $100 \mathrm{~m} \mathrm{~d}^{-1}$ up to $700 \mathrm{~m} \mathrm{~d}^{-1}$ for all three methods. Sinking velocity of agar spheres derived from the orbit analysis showed a good agreement with sinking velocities measured in the sedimentation column as well as in the flow system (Fig. 3a, b). However, sinking velocities measured in the sedimentation column were slightly, but significantly, higher than those measured by the orbit analysis and in the flow system. Sinking velocities measured by the orbit analysis were not significantly different to those measured in the flow system. The average differences of all measurements were $<11 \%$ (Table 1 ).

Diatom aggregates-The comparison between sinking velocities of diatom aggregates determined in roller tanks with those measured in the sedimentation column are shown in Table 2, the ratios of paired measurements are given in Table 3 . Sinking velocities derived from the orbit analysis of roller tanks were similar to those measured in the sedimentation column. By comparison, the method using only two points of the aggregate's trajectories observed in the roller tank showed much higher standard deviations of the mean values obtained (Table 2), and sinking velocities were significantly lower than those measured in the sedimentation column (Table 3). The average ratio between sinking velocity measured in the flow system relative to that measured in the sedimentation column was $0.82 \pm 0.17$ (Table 3 ). This difference was also statistically significant, and was presumably partly explained by nonspherical shape of aggregates as no such large difference was observed for the agar spheres. In the flow system, nonspherical aggregates are oriented with their longest axis perpendicular to the axes of propagation which maximizes the drag of the aggregate. This was not always the case in the sedimentation column.

Size-specific sinking velocities of diatom aggregates as calculated by Eq. 2, and measured using the flow system, the orbit analysis, and the sedimentation column are shown (Fig. 4). The average excess density, which could explain observed sinking velocities, was $0.0014 \mathrm{~g} \mathrm{~cm}^{-3}$ (Eq. 2). Theoretical sinking velocity was described by $U=170 \times \mathrm{d}^{0.82 \pm 0.05}\left(R^{2}=\right.$ $1.00)$, where $U$ is measured in $\mathrm{m} \mathrm{d}^{-1}$ and the diameter, $\mathrm{d}$, is measured in $\mathrm{mm}$.

\section{Discussion}

The methods determining sinking velocity directly in roller tanks are noninvasive methods, and after sinking velocity measurements, incubations can be continued without disturbance due to handling, or the same aggregates can be collected for further analysis. Hence, these methods are superior, e.g., when studying long-term changes in sinking velocity and aggregate composition, or when working with very fragile aggregates. However, only two dimensions of the aggregate size can be determined from the video recordings of aggregates in roller tanks (Engel and Schartau 1999). It is thus not possible to measure volumes and equivalent spherical diameter with high accuracy when using video recordings of aggregates in roller tanks.

Quantification of sinking velocity by the two point method appeared to be sensitive to the fraction of the orbital trajectories chosen. Sinking velocities derived from two-point method tested here showed a larger deviation from those measured 
Table 1. Paired measurements of sinking velocity on single agar spheres using the orbit analysis, the sedimentation column, and the flow system. The average ratio of paired measurements and the standard deviation of the mean value are shown as well as $t$ calculated from Student $t$ test of paired observations.

\begin{tabular}{lcc}
\hline Methods & Ratio & $T$ \\
\hline Orbit analysis versus sed. column & $0.93 \pm 0.10(n=34)$ & $4.34 ;+; P<0.95$ \\
Flow system versus orbit analysis & $0.96 \pm 0.14(n=27)$ & $0.63 ;-; P<0.95$ \\
Flow system versus sed. column & $0.89 \pm 0.15(n=35)$ & $3.15 ;+; P<0.95$ \\
\hline
\end{tabular}

+ , significantly different; -, not significantly different.

Table 2. Average sinking velocity and standard deviation $\left(\mathrm{m} \mathrm{d}^{-1}\right)$ of 6 to 8 diatom aggregates measured in four roller tanks and calculated using the orbit analysis and the two-point method by Engel and Schartau (1999).

\begin{tabular}{lccr}
\hline Roller tank \# & Sedimentation column & Orbit analysis & Two-point method \\
\hline 1 & $288 \pm 46$ & $260 \pm 63$ & $217 \pm 135$ \\
2 & $346 \pm 46$ & $360 \pm 73$ & $\mathrm{Nd}$ \\
3 & $454 \pm 54$ & $427 \pm 21$ & $395 \pm 87$ \\
4 & $286 \pm 23$ & $251 \pm 39$ & $215 \pm 51$ \\
\hline
\end{tabular}

Table 3. Ratio between paired measurements of sinking velocity $\left(\mathrm{m} \mathrm{d}^{-1}\right)$ of diatom aggregates comparing determinations in roller tanks or the flow system with those from the sedimentation column. Roller tank determinations were calculated using the orbit analysis and the two-point method by Engel and Schartau (1999). The average ratio of paired measurements and the standard deviation of the mean value are shown as well as $t$ calculated from Student $t$ test of paired observations.

\begin{tabular}{lcc}
\hline Methods & Ratio & $t$ \\
\hline Orbit analysis versus sed. column & $0.94 \pm 0.07(n=4)^{\star}$ & $1.71(-; P<0.95)$ \\
Two-point method versus sed. column & $0.79 \pm 0.07(n=3)^{\star}$ & $2.44(+; P<0.95)$ \\
Flow system versus sed. column & $0.82 \pm 0.17(n=19)^{\dagger}$ & $4.71(+; P<0.95)$ \\
\hline
\end{tabular}

$n$, number of observations.

*Each observation equaled the average of 6-8 aggregates (Table 2).

†each observation represents one single aggregate.

Sinking velocities varied between $100 \mathrm{~m} \mathrm{~d}^{-1}$ and $500 \mathrm{~m} \mathrm{~d}^{-1}$.

- , not significantly different.

+ , significantly different.

with a sedimentation column than those derived from analysis of the whole orbit. Furthermore, sinking velocity measured by the two-point method is very sensitive to the horizontal distance between the two measuring points. It should always be as small as possible as pointed out by Engel and Schartau (1999). The two-point method is limited to those aggregates that occur close to the front side of the cylinder because the method was not calibrated with depth of the roller tank (Engel and Schartau 1999). The calibration of depth in roller tanks using the orbit method is very important, except when only aggregates at the very front are video recorded. Measured sinking velocity was underestimated by up to $30 \%$ in $12 \mathrm{~cm}$ deep roller tanks that were not calibrated with depth. In summary, the full orbit analysis is mathematically more robust than the two-point method because it uses more observations and is easy to use (given the freely available function 'orbitsink'), especially if aggregates are not too small $(>0.5 \mathrm{~mm})$, and gave highly reproducible results. The two-point method is prefer- ably if aggregates so small that the magnification needed for observation is too high to include the whole orbit of the circling aggregate.

The advantage of the flow system is that it can be used for combined measurements of size (in three dimensions), sinking velocity, and either activity parameters like respiration and bacterial production, or composition of the very same aggregate (Ploug and Grossart 2000; Ploug et al. 2008). Thus the flow system is superior, when measurements are linked to studies of small-scale fluxes of gases and solutes, e.g., $\mathrm{O}_{2}$-respiration, for which it was developed. The local flow velocity in the chamber, however, can vary by $20 \%$ compared with the average flow velocity through the chamber (Ploug and Jørgensen 1999), and the present study shows that sinking velocity of (non-spherical) diatom aggregates is, on average, underestimated by $20 \%$ compared with that measured in a sedimentation column. Small-scale fluxes of gases and nutrients, however, do not increase proportional to sinking veloc- 


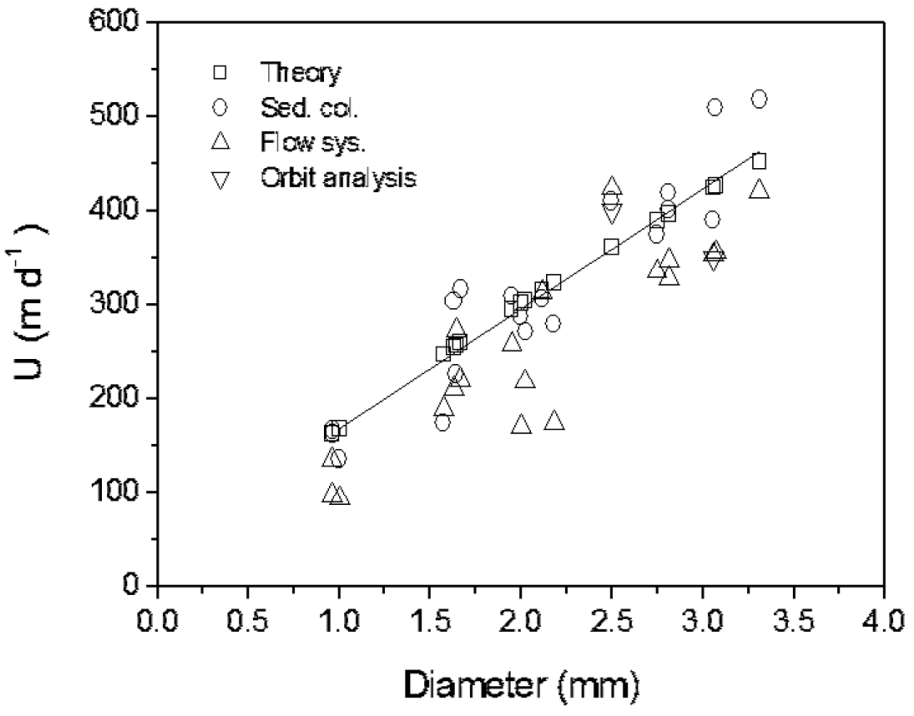

Fig. 4. Sinking velocity of diatom aggregates as a function of equivalent spherical diameter.

ity. We estimated the potential error in small-scale fluxes of $\mathrm{O}_{2}$ to and from sinking aggregates due to the underestimation of sinking velocity by calculating the Sherwood number for size-specific sinking velocities measured in the present study and for a $20 \%$ smaller size-specific sinking velocity. The Sherwood number, $S h$, is a measure of the potential increase in small-scale fluxes at the aggregate-water interface of sinking aggregates compared with that to or from a similar-sized stagnant aggregate. The Sherwood number is described by Kiørboe et al. (2001):

$$
S h=1+0.619 \times\left(\frac{U r_{0}}{v}\right)^{0.421}\left(\frac{v}{D_{0}}\right)^{1 / 3}
$$

where $r_{0}$ is the aggregate radius $(\mathrm{cm})$, and $D_{0}$ is the free molecular diffusion coefficient of the solute and $\mathrm{Re}<20$. The Sherwood number of oxygen mass transfer to sinking diatom aggregates with a size-specific sinking velocity as a function of Re is shown (Fig. 5). Sh is lowered by $3 \%$ to $7 \%$ and by $8 \%$ to $23 \%$ when sinking velocity is underestimated by $20 \%$ and $50 \%$, respectively. Hence, small deviations in sinking velocity are not crucial for mass transfer at intermediate $R e<20$, and sinking velocity determinations using the flow velocity chamber are accurate enough in the context of small-scale flux measurements.

A sedimentation column is simple to use, but has the disadvantage that replicate measurements of aggregate sinking velocity are impossible because the aggregates are fragile and easily disaggregate when collected at the bottom of the cylinder. Convective currents due to evaporation at the air-water interface can lead to overestimation of sinking velocity, which may also have occurred during our measurements. This problem can be solved by closing the cylinder in the top except for a small inlet (Johnson et al. 1996; Li et al. 2003; Ploug et al. 2008).

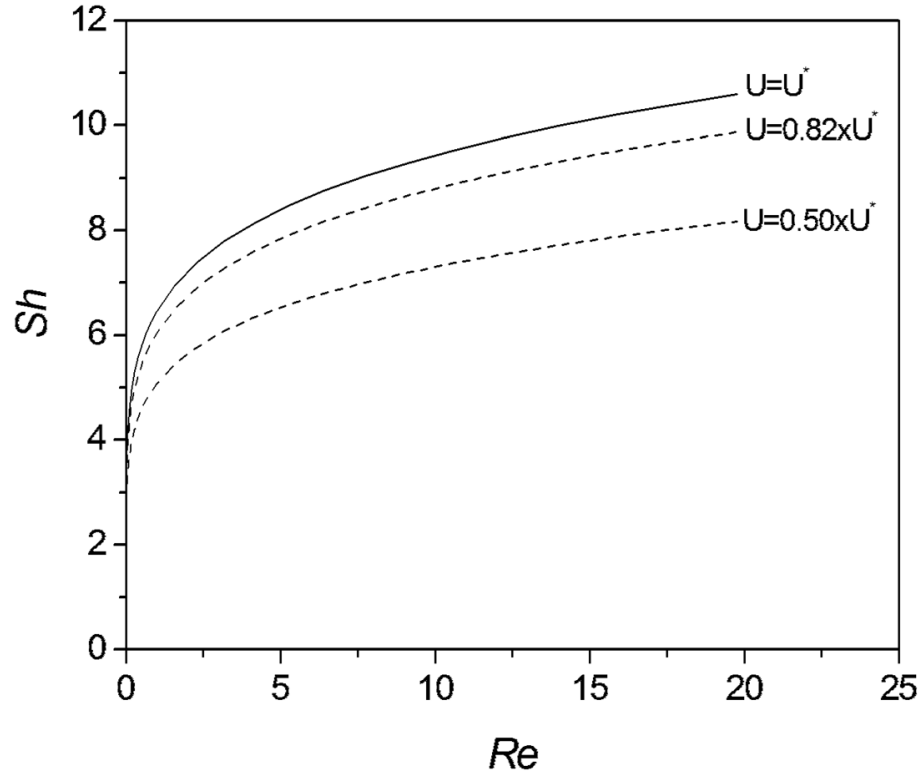

Fig. 5. Sherwood number (Sh) as a function of Reynolds number (Re). Re was calculated on basis of $U^{*}$, which here refers to true sinking velocity.

\section{Comments and recommendations}

In all methods used in this study, it is important to use a cold light source with a cut-off infrared filter. Replicate measurements of sinking velocities calculated from their orbit in roller tanks varied significantly when video recordings were performed without an infra red cut-off filter in front of the light source.

Very small differences in salinity and temperature between aggregate pore water and the bulk water are crucial factors determining excess density and thus sinking velocity. We observed that agar spheres and aggregates needed to equilibrate for app. 15 to $20 \mathrm{~min}$ in the flow system before sinking velocity was constant. This equilibration time compares well with the theoretical diffusion time of salt ions in $3 \mathrm{~mm}$ large aggregates. This problem can easily arise when aggregates are introduced from one system to another, e.g., from a roller tank to a sedimentation column or a flow system. This problem does not arise when using orbit analysis in roller tanks to measure sinking velocity from video recordings because these methods are truly non-invasive, and aggregate sinking velocity is measured (at solid body rotation) directly within the same medium of which the aggregates are formed.

\section{References}

Alldredge, A. L., and C. C. Gotschalk. 1988. In situ settling behavior of marine snow. Limnol. Oceanogr. 33:339-351 [doi:10.4319/lo.1988.33.3.0339].

— culation of diatom blooms: Characteristics, settling velocities and formation of diatom aggregates. Deep-Sea Res. 36:159-171 [doi:10.1016/0198-0149(89)90131-3]. —, and M. Silver. 1988. Characteristics, dynamics and sig- 
nificance of marine snow. Prog. Oceanogr. 20:41-82 [doi:10.1016/0079-6611(88)90053-5].

Asper, V. L. 1987. Measuring the flux and sinking speed of marine snow aggregates. Deep-Sea Res. 34:1-17 [doi:10.1016/0198-0149(87)90117-8].

Azetsu-Scott, K., and U. Passow. 2004. Ascending marine particles: significance of transparent exopolymer particles (TEP) in the upper ocean. Limnol. Oceanogr. 49:741-748.

Berelson, W. M. 2002. Particle settling rates increase with depth in the ocean. Deep Sea Res. II 49:237-251 [doi:10.1016/S0967-0645(01)00102-3].

Billet, D. S. M., R. S. Lampitt, A. L. Rice, and R. F. C. Mantoura. 1983. Seasonal sedimentation of phytoplankton to the deep sea benthos. Nature 302:520-522 [doi:10.1038/302520a0].

Cronenberg, C. C. H. 1994. Biological engineering on a microscale: Biofilms investigated with needle-type glucose sensors. Ph. D. thesis, Univ. of Amsterdam.

Engel, A., and M. Schartau. 1999. Influence of tranparent exopolymeric particles (TEP) on sinking velocity of Nitzschia clostridium aggregates. Mar. Ecol. Prog. Ser. 182:69-76. [doi:10.3354/meps182069].

Guillard, J. K., and J. H. Ryther. 1962. Studies of marine planktonic diatoms. I. Cyclotella nana (Hustedt) and Detonula confervacea (Cleve) Gran. Can. J. Microbiol. 8:229-239 [doi:10.1139/m62-029].

Jackson, G. A. 1994. Particle trajectories in a rotating cylinder: implications for aggregation incubations, Deep-Sea Res. I 41(3):429-437 [doi:10.1016/0967-0637(94)90089-2].

Johnson, C. P., X.-Y. Li, and B. E. Logan. 1996. Settling velocities of fractal aggregates. Environ. Sci. Tech. 30:1911-1918 [doi:10.1021/es950604g].

Khelifa, A., and P. S. Hill. 2006. Models for effective density and settling velocity of flocs. J. Hydraulic Res. 44:390-401.

Kiørboe, T., H. Ploug, and U. H. Thygesen. 2001. Fluid motion and solute distribution around sinking aggregates. I. Small scale fluxes and heterogenity of nutrients in the pelagic environment. Mar. Ecol. Prog. Ser. 211:1-13 [doi:10.3354/ meps211001].

Li, X.-Y, Y. Yuan, and H.-W. Wang. 2003. Hydrodynamics of biological aggregates of different sludge age: an insight into mass transport mechanisms of bioaggregates. Environ. Sci. Tech. 37:292-299 [doi:10.1021/es020764+].
Logan, B. E., and D. B.Wilkinson. 1990. Fractal geometry of marine snow and other biological aggregates. Limnol. Oceanogr. 35:130-136 [doi:10.4319/lo.1990.35.1.0130].

Ploug, H., and B. B. Jørgensen. 1999. A net-jet flow system for mass transfer and microelectrode studies in sinking aggregates. Mar. Ecol. Prog. Ser. 176:279-290 [doi:10.3354/meps 176279].

—, and H.-P. Grossart. 2000. Bacterial growth and grazing on diatom aggregates: Respiratory carbon turnover as a function of aggregate size and sinking velocity. Limnol. Oceanogr. 45(7):1467-1475.

, S. Hietanen, and J. Kuparinen. 2002. Diffusion and advection within and around sinking, porous diatom aggregates. Limnol. Oceanogr. 47:1129-1136.

—, M. H. Iversen, and G. Fischer. 2008. Ballast, sinking velocity, and apparent diffusivity within marine snow and fecal pellets: Implications for substrate turnover by attached bacteria. Limnol. Oceanogr. 53:1878-1886.

Simon, M., H.-P. Grossart, B. Schweitzer, and H. Ploug. 2002. Microbial ecology of organic aggregates in aquatic ecosystems. Rev. Aquat. Microb. Ecol. 28:175-211.

Tooby, P. F., G. L. Wick, and J. D. Isaacs. 1977. The motion of a small sphere in a rotating velocity field: a possible mechanism for suspending particles in turbulence. J. Geophys. Res. 82(13):2096-2100 [doi:10.1029/JC082i015p02096].

Turner, J. T. 2002. Zooplankton fecal pellets, marine snow, and sinking phytoplankton blooms. Aquat. Microb. Ecol. 27:57102 [doi:10.3354/ame027057].

Volk, T., and M. I. Hoffert. 1985. Ocean carbon pumps: analysis of relative strengths and efficiencies in ocean-driven atmospheric CO2 changes, pp. 99-110. In: E. Sundquist and W. S. Broecker, [Eds.], The carbon cycle and atmospheric CO2: Natural variations archean to present. AGU.

White, F. M. 1974. Viscous fluid flow. McGraw-Hill.

Ziervogel, K., and S. Forster. 2005. Aggregation and sinking behavior of resuspended fluffy layer material. Cont. Shelf. Res. 25:1853-1863 [doi:10.1016/j.csr.2005.06.008].

Submitted 25 June 2009 Revised 7 May 2010 Accepted 14 May 2010 